\title{
A Conceptual Framework for Consumer Information Systems Development
}

\author{
Tuure Tuunanen \\ University of Oulu, Finland \\ Center of Service Leadership \\ Arizona State Univ., USA \\ tuure@tuunanen.fi \\ Michael D. Myers \\ The University of Auckland Business School \\ New Zealand \\ m.myers@auckland.ac.nz \\ Harold Cassab \\ The University of Auckland Business School \\ New Zealand \\ h.cassab@auckland.ac.nz
}

\begin{abstract}
Consumer information systems (CIS) are an emerging area of inquiry for information systems researchers. IS researchers have traditionally emphasized efficiency and effectiveness of organizational processes and system use. However, design for consumer information systems requires more attention to be paid to processes of value creation embedded in the consumer experience. This shift in focus demands a reconsideration of current information systems development approaches. In this paper we propose a conceptual framework for consumer information systems development. The framework includes six elements of co-creation of consumer value. The framework is illustrated by reviewing the findings from three case studies.
\end{abstract}

Keywords: Consumer information systems development, value co-creation, consumer experience, and case study. 


\section{Introduction}

In recent years research into services (IfM and IBM, 2008) has started to attract the attention of scholars from many different disciplines. The importance of research into services is easily justified - developed countries have moved from the industrial age to become service dominant economies, and a major portion of gross national product is now in the service industries. According to the Organization for Economic Cooperation and Development (OECD), over $60 \%$ of economic activity in OECD countries is driven by services (Wölfl, 2005).

This shift to a service-oriented economy has implications for IS researchers. First, there is an emerging trend in service research to consider new ways of enhancing the design and development of digitized services [Ostrom et al., 2010]. Second, information systems (IS) are increasingly being targeted to consumers of these services. Third, much research in consumer psychology, behavioral psychology and marketing indicates that consumption is motivated by the predicted utility of the good or service. Consumers use rational and emotional-based assessments of utility in their predictions [Shiv and Fedorikhin, 1999]. Thus, the object of consumption will have utilitarian and/or hedonic value from the consumer perspective. This suggests the need for a new approach to the development of digitized services for consumers.

In the IS research literature, users of information systems have often been conceptualized as being mostly concerned about the effectiveness and efficiency of their work performance and processes [Lamb and Kling, 2003] in an organizational setting. Consumers, however, seek a balance of utilitarian and hedonic utility [Agarwal and Karahanna, 2000, Holbrook et al., 1984, Shiv and Fedorikhin, 1999], where the latter corresponds to the enjoyment associated with using the product or service. Consumers also start to become active participants in the production of goods and services they consume (Ostrom et al., 2010) and become co-creators of value (Vargo and Lusch, 2004) throughout the service experience. Thus, the service offering (Grönroos, 2007, Menor et al., 2002) takes priority over everything else, and becomes more important that the functionality or effectiveness of the product. This change in priorities requires a change in the way we design and develop IS solutions.

We therefore suggest that we are entering a new era of consumer information systems. We need to start designing and developing systems for consumers, as contrasted with users. We believe the trend towards the development of digitized services potentially marks a disruption both in the practice and research of information systems.

We define consumer information systems (CIS) as follows:

Systems that enable consumer value co-creation through the development and implementation of information technology enabled processes that integrate system value propositions with customer value drivers.

This definition comprises both the service nature and the information technology (IT) basis for CIS. The notion of co-creation of value (an important concept in marketing) with CIS users is particularly relevant because it highlights a disruption with the traditional view of information systems development. It also opens up interesting avenues for research on system and service quality of CIS, since it incorporates both consumers and developers as active participants in the value creation process. We also suggest that it may be possible to combine the insights from the literature on IS development with the insights from service marketing research, especially in the area of service design, to help with the discovery and definition of requirements for consumer information systems.

Our paper thus proposes a conceptual framework for consumer information systems development. The framework illustrates how consumer value is co-created through system value propositions and customer value 
drivers. Our framework is illustrated by reviewing the findings from three case studies.

\section{Consumers' Requirements and Value Propositions}

Various disciplines have dealt with issues surrounding the problem of recognizing the needs of users of services and products. In information systems the traditional approach has been to determine the needs of the organizational end-user and then to analyze user data in order to specify requirements of feasible quality (Browne and Rogich, 2001, Byrd et al., 1992, Davis, 1982, Hickey and Davis, 2004, Keil and Carmel, 1995, Mathiassen et al., 2007). This has led to the development of various requirements elicitation techniques to help the analyst to understand users.

It has been suggested that users should be reconceptualized as "actors" (Lamb, 2005, Lamb, 2006, Lamb and Kling, 2003). According to Lamb and Kling, the term "actor" better encompasses the networked nature of modern work life. Individuals do not work in isolation but rather work in teams. Lamb and Kling (2003) also claim that actors can potentially have an identity (Creed et al., 2002, Simon et al., 2009) attached to the IT artifacts they use. Lamb and Kling argue that actors use these IT artifacts to form and construct identities for themselves. For instance, Japanese teenagers accessorize their mobile phones with different gizmos and costume jewelry, making mobile phones part of their identity.

Other researchers have suggested that the context of system use (Dey and Abowd, 2000, Goodhue, 1995, Orlikowski et al., 1995, Schilit et al., 1994) is also an important issue. These authors argue that context of use is very likely to affect the user experience. Other researchers have argued that cultural context is likely to influence user requirements (Tuunanen et al., 2006) and system use (Myers, 1999, Myers and Tan, 2003).
To summarize, there are several aspects of consumer behavior that potentially influence the process of understanding requirements for consumers of information systems. First, there is the social nature of system use. Consumers rarely use any information system in isolation (Lamb and Kling, 2003); rather, they look for ways to network and interact with other users. The rapid growth of social networking systems (e.g., Facebook and Twitter) illustrates this consumer need.

Second, consumers are likely to relate to the services they use and they may create and/or alter their identities in real and virtual lives. For example, Apple has been very successful in attaching an identity of 'coolness' to its devices and services. Apple's value proposition includes the "coolness" factor and the identity that comes with it.

Third, context affects IS consumer behavior. Developers are often unable to predict the actual use of developed systems. Text messaging is a good example of this. The Finnish engineer who originally developed text messaging considered that this technology would only be good for service messaging purposes between cell tower base stations. The vision was rather limited given that there are today billions of text messages sent every day. The context of system use created numerous opportunities for the technology: consumers to interact with each other, buy bus and train tickets, pay for parking, and order information services such as weather reports. Thus, the context of use, both cultural and situational, has a greater impact on the use of CIS than the business and/or organizational uses of information systems. Table 1 summarizes consumers' requirements and these value propositions.

\section{Customers' Value Drivers}

CIS development naturally shares many similar features with traditional information systems development. However, some aspects related to customer value are different if we consider CIS development and use. 


\begin{tabular}{|c|l|l|}
\hline \multicolumn{2}{|c|}{ Table 1 - Consumers' Requirements and Value Propositions } \\
\hline $\begin{array}{c}\text { Aspect of } \\
\text { consumer } \\
\text { behavior }\end{array}$ & \multicolumn{1}{|c|}{ Theoretical basis } & \multicolumn{1}{c|}{ Examples } \\
\hline $\begin{array}{c}\text { Social nature of } \\
\text { use }\end{array}$ & $\begin{array}{l}\text { Social Actor Theory [Lamb, 2005, Lamb, 2006, } \\
\text { Lamb and Kling, 2003], Political Ecology of } \\
\text { Requirements (Bergman et al., 2002). }\end{array}$ & $\begin{array}{l}\text { Social networking services such as Facebook, } \\
\text { MySpace etc. Text messaging has been widely } \\
\text { adopted and is more popular than email in some } \\
\text { parts of world. }\end{array}$ \\
\hline $\begin{array}{c}\text { Construction of } \\
\text { identities }\end{array}$ & $\begin{array}{l}\text { Social Actor Theory (Lamb, 2005, Lamb, 2006, } \\
\text { Lamb and Kling, 2003), Social Construction of } \\
\text { Identity (Creed et al., 2002, Simon et al., 2009). }\end{array}$ & $\begin{array}{l}\text { Customization of Mobile phones with unique } \\
\text { services and accessories; applications that } \\
\text { provide services such as Apple's AppStore. }\end{array}$ \\
\hline \multirow{2}{*}{$\begin{array}{c}\text { Context of use } \\
\text { Context of Information Systems Use (Goodhue, }\end{array}$} & $\begin{array}{l}\text { 1995, Orlikowski et al., 1995), Context Aware } \\
\text { Computing (Dey and Abowd, 2000, Schilit et al., } \\
\text { 1994). Cultural context (Myers, 1999, Myers } \\
\text { and Tan, 2003, Tuunanen et al., 2006). }\end{array}$ & $\begin{array}{l}\text { Thental start of text messaging: Text } \\
\text { messaging was developed for a limited purpose } \\
\text { - as a technical service-messaging tool between } \\
\text { cellular base stations. Yet today billions of text } \\
\text { messages are sent every day. }\end{array}$ \\
\hline
\end{tabular}

A central premise in the Marketing and New Product Development literature has been the need to incorporate the voice of the customer (Griffin and Hauser, 1993) in the development process to ensure customer acceptance. Holbrook et al. (1984), in their study of the effect of emotions, performance and personality on value creation in games, proposed the notion of 'playful consumption' where play becomes part of the consumption experience. More recently, behavioral psychologists such as Kahneman et al. (2003) have suggested that consumers not only derive utility from consumption, but also benefits of a hedonic nature. Similarly, it has been suggested (Agarwal and Karahanna, 2000, Csikszentmihaly, 1991, Hill et al., 2002) that an experience of flow in service or system use is important to users, as are emotions elicited during use.

The flow concept can be illustrated by the development of the Halo III video game. Microsoft developers analyzed 3,000 hours of Halo III played by over 600 everyday gamers, tracking everything from favored game features used in different situations to the gamers' experience of 'game over' situations as their characters died in the game (Thompson, 2009). Microsoft also observed gamers playing onsite. Participants were asked every few minutes how they would rate their engagement, interest, or frustration with the game. They were also asked to talk out loud about what they were experiencing, providing a stream-of-consciousness record of their thought processes as they played. Using the flow concept, Microsoft developers were able to use the results of this research to ensure an engaging experience for game players (Thompson, 2009).

The implications of customer participation have been debated within the research literature concerning services marketing (Vargo and Lusch, 2004). According to Vargo and Lusch (2004), service dominant logic means a change from firms providing services of pre-determined value to a new landscape where firms only make value propositions; value is co-created and the total value of the offering is determined by the customer in use. This phenomenon has been especially evident with computer gaming (Karlsen, 2008). Moreover, consumers now expect more personalized experiences.

Information systems researchers have long promoted participation of users in development (see, e.g., Davis, 1982, Goodhue, 1995, Herzwurm et al., 1997). Although researchers agree that user participation is beneficial, especially in the requirements elicitation and analysis phases 
of the project, there is still some uncertainty about the best ways to involve users (Cavaye, 1995, Hartwick and Barki, 1994, Kujala, 2003, Kujala et al., 2001, McKeen and Guimaraes, 1997, Tait and Vessey, 1988. Most studies have focused on users in organizational settings. There are, however, some studies which have explicitly taken a consumer focus. For example, Von Hippel et al. (1986, 2001, 2002) suggested engaging potential leadusers of a product or service via toolkits that could be implemented with virtual communities. These toolkits include online tools for product design, prototyping and testing. Tuunanen and Rossi [2004] proposed the use of rapid prototyping, where a consumer would design, for example, a mobile application online by using simple modeling tools to "drag and drop" desired features to the application framework. Another scenario that illustrates user involvement comes from on-demand video streaming services where it is now possible for a viewer to influence the programming in real time.

However, we still have the question of determining how system features can create hedonic utility (Kahneman et al., 2003) through the CIS use experience. Quality function deployment techniques [Herzwurm et al., 1997] have been used to ensure that product or service features are linked to customer needs. Quality function deployment has been widely used in industries ranging from car manufacturing to health insurance. Jacobs and Ip (2003) investigated how to use quality function deployment to match computer and console gamers to games. Their research shows differences between gamer segments and consumers' game feature desires, but it does not provide linkages between hedonic utility derived from gaming and game features in order to enable its measurement. In the IS research literature, there is a strong tradition of using perceived usefulness of information systems as a success metric [Venkatesh et al., 2003]. In marketing, the conjoint approach has been used to measure consumer trade-offs and utility associated with product or service features (Green and Srinivasan, 1990, Ostrom and lacobucci, 1995).

An industry example of hedonic utility is the Fluid application for the iPhone ${ }^{1}$. Although not particularly efficient or useful, this application is very popular (iWorthlt, 2009). A reviewer of the application says:

"Essentially, it's a pond with the water making small waves on the surface. With your fingers you can act like you're dipping your finger in the water and make a ripple effect. Additionally, you can change the background on it to any picture you have on your phone and make funny waves on it."

What is surprising is that this application has been downloaded from Apple's AppStore three million times as of June 2009 even though it has no functional utility whatsoever.

In summary, we suggest there are three key challenges regarding $\mathrm{CIS}$ and co-creation of value (see Table 2). First, although IS researchers have been dealing with IS development for decades, there are still unanswered questions regarding the service process experience in CIS - how and when to encourage consumer involvement and participation in the system development process (see, e.g., Kujala, 2003). This is even more challenging in CIS development due to its service nature and differences in motivation to contribute (consumers versus members of an organization). The existing literature is silent on this issue. The integration of flow experience of the developed service might provide some answers. Second, there are challenges with respect to customer participation in service production. Co-creation of value has been suggested in the service literature as an outcome of consumer involvement (Ostrom et al., 2010). Third, customer goals and outcomes are a challenge for CIS. How can information systems be developed with features that enable consumers to experience hedonic benefit from their CIS usage, and how can this effect be measured? 


\begin{tabular}{|c|c|c|}
\hline Challenge & Theoretical basis & Examples \\
\hline $\begin{array}{l}\text { Service Process } \\
\text { Experience }\end{array}$ & $\begin{array}{l}\text { The Psychology of Optimal Experience } \\
\text { (Csikszentmihaly, 1991), Consumption Patterns } \\
\text { (Westbrook and Oliver, 1991), Cognitive absorption } \\
\text { (Agarwal and Karahanna, 2000) }\end{array}$ & $\begin{array}{l}\text { The development of Halo III video } \\
\text { game by Microsoft, which used the flow } \\
\text { concept to ensure smooth game } \\
\text { experience with extensive in-game } \\
\text { data analysis. }\end{array}$ \\
\hline $\begin{array}{l}\text { Customer } \\
\text { Participation in } \\
\text { Service } \\
\text { Production }\end{array}$ & $\begin{array}{l}\text { Service dominant logic (Vargo and Lusch, 2004), } \\
\text { service/system co-production (Karlsen, 2008, } \\
\text { Pedersen, 2005), lead-user engagement [von Hippel, } \\
\text { 1986, von Hippel, 2001, von Hippel and Katz, 2002] }\end{array}$ & $\begin{array}{l}\text { Co-creation of on-demand video } \\
\text { streaming services when consumers } \\
\text { actively affect the TV service content } \\
\text { real time, such as voting for political } \\
\text { candidates. }\end{array}$ \\
\hline $\begin{array}{l}\text { Customer Goals } \\
\text { and Outcomes }\end{array}$ & $\begin{array}{l}\text { Hedonic Utility (Holbrook et al., 1984, Kahneman et } \\
\text { al., 2003), User Acceptance of Information } \\
\text { Technology (Venkatesh et al., 2003), Consumer } \\
\text { trade-offs (Green and Srinivasan, 1990, Ostrom and } \\
\text { lacobucci, 1995) }\end{array}$ & $\begin{array}{l}\text { Fluid iPhone application that does not } \\
\text { have any functional utility, yet provides } \\
\text { hedonic benefit to users. }\end{array}$ \\
\hline
\end{tabular}

\section{Value Co-Creation in Consumer Information Systems}

Figure 1 summarizes our proposed framework for value co-creation in CIS. The framework is divided in two sections. The left side of the framework depicts CIS value propositions, whereas the right side depicts customer value drivers. The six factors are drawn from the research literature in information systems, marketing and service research.
Three factors related to CIS value propositions are summarized in Figure 1: construction of identities, social nature of use, and context of use. These concepts originate from social actor theory (Lamb and Kling, 2003), contextual use of information systems (Dey and Abowd, 2000, Goodhue, 1995, Orlikowski et al., 1995, Schilit et al., 1994), and culture's effect on user behavior (Myers, 1999, Myers and Tan, 2003), and users' needs (Tuunanen et al., 2006).

\section{System Value Propositions}

Customer Value Drivers

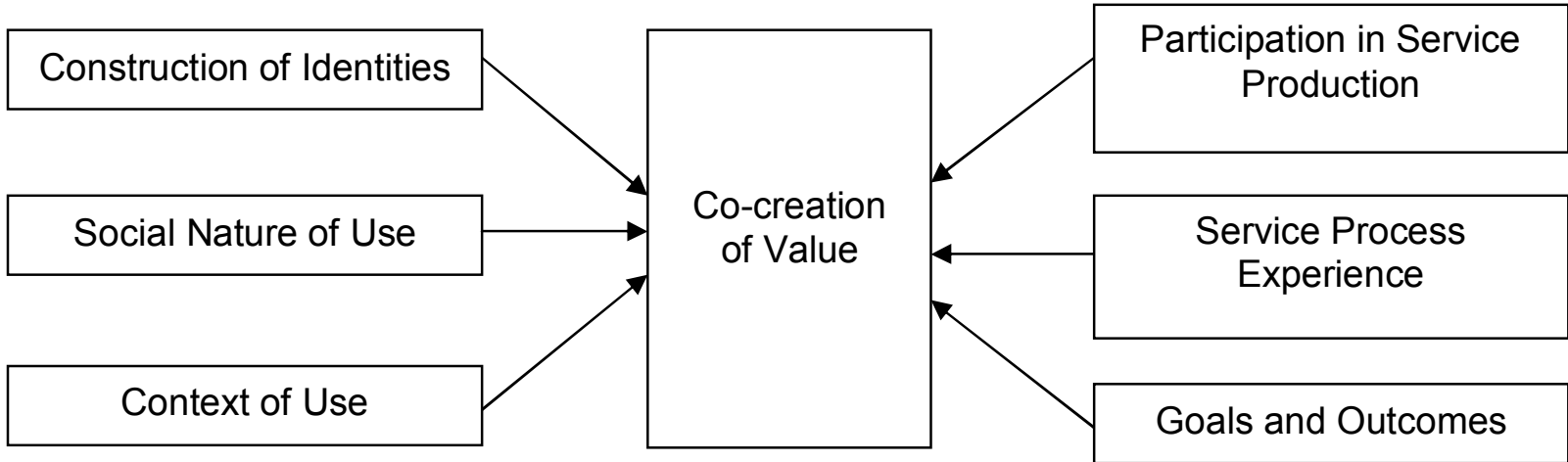

\section{Figure 1 - Framework for Value Co-Creation in Consumer Information Systems}


Three factors are related to customer value drivers (previously summarized in Table 2). These factors are oriented towards the development process of CIS. For example, although the literature agrees that users should be involved in the development process, there is still debate about proper execution of customer involvement (Cavaye, 1995, Hartwick and Barki, 1994, Kujala, 2003, Kujala et al., 2001, McKeen and Guimaraes, 1997, Tait and Vessey, 1988). The flow concept appears relevant. Current flow studies, however, have not considered events that take place within a functioning service or system (Agarwal and Karahanna, 2000).

In the marketing research literature, value cocreation has been proposed as a central factor for successful service development. Due to its service nature, consumer information systems are poised to benefit from the integration of consumer input into their development. At the same time, there are implementation challenges in codeveloping with consumers who may or may not be willing to provide their inputs. Consequently, the role of customer goals and expected outcomes of service raises a tri-fold question: When, how, and what to measure? In previous studies with technology acceptance models (TAM) and its variants (Venkatesh et al., 2003) the focus has been on efficiency gains in organizational environments. The TAM model is unlikely to be relevant when measuring CIS use.

\section{Some Findings on Value Co- Creation in CIS}

This section provides some initial answers to some of the challenges we have mentioned for consumer information systems development. For this purpose, we review three case studies that were conducted during 2000-2009. All three studies have a similar basis and focus.

All three case studies employed a modified version of the critical success factors approach (Peffers et al., 2003) as an aid in data collection. The in-depth laddering interviewing technique was also used
(Browne and Ramesh, 2002, Browne and Rogich, 2001, Gengler and Reynolds, 1995, Peffers et al., 2003, Reynolds and Gutman, 1988). The laddering technique uses simple open-ended questioning to reveal attribute (feature) - consequence (reasoning) - and value/objective structures of participants for a given topic. The theoretical basis for the method lies in personal construct theory (Kelly, 1955) and critical success factors (Rockart, 1979). Full details of how to apply and use the critical success chains method can be found from (Peffers et al., 2003, 2005).

For data analysis, a clustering technique was used whereby results are represented with network maps containing aggregated understanding of participants' view of the world and their mental models. Further details of each case study are provided elsewhere: Mobile Financial Service (Peffers et al., 2003, 2005), Mobile Presence Services (Tuunanen et al., 2006), and Interactive Television Services (Tuunanen et al., 2010).

The focus of the analysis in all three studies was the perceived user of a yet-to-be developed CIS. In each of the cases the analysis was done from the perspective of a systems analyst. The context and the industry domain vary in each of the cases as described below. These studies provide some answers to the challenges of value cocreation in consumer information systems.

\section{Case Study 1: Mobile Financial Services}

Description. Digia Corporation in Finland initiated this project conducted during 20002001. Researchers were given the task of identifying features of third generation mobile phone services for the financial sector. These services were to be used by consumers of yet to-be-launched third generation smart phones, similar to current BlackBerrys, Apple iPhones, and Nokia E- and S-series smart phones. Researchers worked with prototypes and sketches of such devices, as well as ideas of what the technology might enable consumers to do with their devices. The task was to find "financial killer applications for 3G mobile phones". Digia had conducted a strategic 
analysis of the potential market and considered that it would be very lucrative for the firm to develop services for consumers of smart phones.

Data collection. Digia Corporation did not have experience with consumer products or services and had no consumer base to approach for requirements discovery purposes. Therefore, researchers proposed the use of the lead-user approach (von Hippel, 1986) combined with snowball sampling
(Olson and Bakke, 2001) for recruiting participants to the study. The initial sample consisted of four key informants in the client organization who, in turn, recommended potential participants outside of the organization. There were some concerns about lead-user biases and the scalability of this approach [Rogers, 1995]. However, Digia deemed the project as a "blue sky" research project and agreed to use the approach despite its possible limitations.

\begin{tabular}{|c|c|c|}
\hline \multicolumn{3}{|l|}{ Age } \\
\hline & $20-29$ yrs & 12 \\
\hline & $30-39$ yrs & 14 \\
\hline & $40-y r s$ & 6 \\
\hline \multicolumn{3}{|l|}{ Education } \\
\hline & Bachelor & 10 \\
\hline & Masters & 18 \\
\hline & Doctorate & 4 \\
\hline \multicolumn{3}{|l|}{ Gender } \\
\hline & Male & 27 \\
\hline & Female & 5 \\
\hline
\end{tabular}

In order to understand and discover the tacit needs of consumers of mobile financial services, thirty-two in-depth laddering interviews were conducted with potential lead-users. Demographics of the participants are depicted in Table 3 above. The majority of the participants were under forty years old and all of the participants had a university degree. More than half of the participants also had a graduate degree, which is typical for professionals in Finland. The participants' gender was male dominated, similar to the other two case studies.

Findings. The findings of the study were very encouraging. Digia was able to develop concept prototypes for future mobile financial services (Peffers and Tuunanen, 2005). Although only potential lead users were used as participants in the study, the particular requirements discovery technique complemented the selected participant sampling technique. Laddering interviews provided a rich set of contextual information about the perceived system use including systems features, the reasoning why participants would want to use such features, and the values and goals of system use. There were more than 1000 individual requirements in the data set. The requirements were further analyzed and 114 system features were developed. These were grouped into five conceptual feature sets. Furthermore, the enthusiastic participation of the interviewees indicates that the lead-user approach is complementary to the use of the laddering in-depth interviewing technique. The potential lead-users were eager to share their views regarding future services and 
almost all participants asked to see the final report when it was completed. Finally, according to the Digia product analyst, the firm considered the method to be useful for a number of reasons. First, the method seems to work well and it is easy to see why it works; second, the interviewer collecting data for the method needs no special abilities or skills, and third, the resulting graphical maps are very helpful in understanding how people think about an issue. Full details of the study are available at (Peffers and Tuunanen, 2005).
The two techniques were thus able provide insights about 1) how to understand the context of system use when the majority of the users are consumers and 2) how consumers can be engaged in systems development work. However, there is a potential feature bias of lead users versus non-lead users. Lead-users may be interested in more advanced features of the system, application or service than others. This may lead to false prioritization of the requirements.

\begin{tabular}{|c|c|c|c|}
\hline $\begin{array}{l}\text { Framework } \\
\text { Element(s) }\end{array}$ & $\begin{array}{l}\text { Theoretical } \\
\text { Approach }\end{array}$ & Findings & $\begin{array}{l}\text { Future research } \\
\text { topics }\end{array}$ \\
\hline Context of use & $\begin{array}{l}\text { In-depth Laddering } \\
\text { interviews (Peffers et } \\
\text { al., 2003). }\end{array}$ & $\begin{array}{l}\text { Personal in-depth interviews provided } \\
\text { a rich set of contextual information } \\
\text { about the perceived system use } \\
\text { including systems features, reasoning } \\
\text { why participants would want to use } \\
\text { such features, and values and goals of } \\
\text { system use. }\end{array}$ & $\begin{array}{l}\text { Use of other } \\
\text { cognitively rich } \\
\text { requirements } \\
\text { discovery } \\
\text { techniques, such as } \\
\text { contextual design or } \\
\text { ethnographic } \\
\text { research. }\end{array}$ \\
\hline $\begin{array}{l}\text { Participation in } \\
\text { Service } \\
\text { Production }\end{array}$ & $\begin{array}{l}\text { Use of potential lead- } \\
\text { users (von Hippel, } \\
\text { 1986) of the mobile } \\
\text { service }\end{array}$ & $\begin{array}{l}\text { The lead user method and snowball } \\
\text { sampling provide anecdotal evidence } \\
\text { for its efficacy for participation. The } \\
\text { use of laddering as an interviewing } \\
\text { technique supported participation. }\end{array}$ & $\begin{array}{l}\text { Potential feature bias } \\
\text { of lead users versus } \\
\text { non-lead users. The } \\
\text { efficacy of using } \\
\text { snowball sampling } \\
\text { for participant } \\
\text { recruitment. }\end{array}$ \\
\hline
\end{tabular}

Another issue with the lead-user approach is the efficacy of snowball sampling. Olson and Bakke (2001) have argued against this approach as they find that it is often difficult to find "fresh" lead-users for development projects. Therefore we caution that these two techniques should not be thought of as the only solutions for such development situations. Other requirements discovery techniques could be considered, such as contextual design (Holtzblatt and Beyer, 1993, Holtzblatt and Jones, 1996) or ethnographic research techniques. The key findings for this study are summarized in Table 4.

\section{Case Study 2: Mobile Presence Services}

Description. The Mobile Presence Services project [Tuunanen et al., 2006] was a joint venture of more than twenty Finnish organizations interested in digital marketing. The study began in 2004 and it was concluded in 2007. Nokia was the key participant in the project as at the time the company was investigating a new mobile service called mobile presence. The idea was to include "presence" status information to the contact list of a mobile phone. This service would enable a person to see if his or her colleagues were available for a chat or voice call etc. The project was therefore using a 
technology platform that was not available to public at that time. The technology was in beta-testing phase and the technology had not been sold to any telecom operators. Nokia was especially interested in how consumers might want to use "presence status" information besides their basic contact list. Nokia had only a limited understanding of what these mobile service features would be or how they might differ in various cultures or geographic locations around the world.
Data collection. Eighty-one in-depth laddering interviews were conducted with perceived potential lead-users of such services in Helsinki, Hong Kong and Las Vegas. Table 5 below summarizes the demographic information of the participants. The data sets varied according to the location with the exception of gender. In all locations far more males participated than females.

\begin{tabular}{|c|c|c|c|c|}
\hline & & Helsinki & Hong Kong & Las Vegas \\
\hline \multicolumn{5}{|l|}{ Age } \\
\hline & Under 20 & 3 & & 3 \\
\hline & $20-29$ & 17 & 19 & 3 \\
\hline & $30-39$ & 2 & 8 & 8 \\
\hline & $40-49$ & 5 & & 5 \\
\hline & $50-59$ & & & 7 \\
\hline \multicolumn{5}{|l|}{ Education } \\
\hline & Secondary & 22 & 1 & 12 \\
\hline & Tertiary & 3 & 10 & 8 \\
\hline & Post Graduate & 2 & 16 & 6 \\
\hline \multicolumn{5}{|l|}{ Gender } \\
\hline & Female & 2 & 9 & 6 \\
\hline & Male & 26 & 18 & 20 \\
\hline $\begin{array}{l}\text { Missing/ incomplete } \\
\text { demographics }\end{array}$ & & 1 & & \\
\hline
\end{tabular}

In Hong Kong, the participants were more educated than elsewhere. In Las Vegas, the age distribution was more biased towards people older than thirty years. These differences can be traced to the snowball sampling used. As the local field researcher initiated the snowball recruitment, the participant demographics tended to resemble to the demographics of the field researcher (with exception of Helsinki).

Findings. The final requirements specification included nearly 3500 individual requirements, which were then prioritized using cluster analysis and rank-order information of requirements derived from the interviewees. The analysis provided graphical illustrations of how consumers view such services in terms of features, but what is more interesting, the reasoning behind them and the values that drove their needs for such features. The outcome of the study was six conceptual mobile services that utilized presence technology in an innovative way. For example, "Information Access for Special Interest Groups" is a service concept which helps users who are members of special interest groups, such as clubs, churches or professional organizations, to coordinate their activities and behavior. Another service concept was "City Reporter" that focuses on how timely current information on city events, restaurants, and entertainment would be valuable to users. Finally, "Presence 
Messaging" focuses on communicating the location of the user for better relationships and communication potentially leading to more efficient performance and economic gains. More details about the service concepts can be found from (Tuunanen et al., 2006).

Table 6 summarizes the differences between the requirements of the three example service concepts. The numbers depict the origin of individual requirements that were incorporated in the development of the service concept. We also provide results of two-tailed t-tests and the percentage the particular service concept commanded in the complete set of the requirements. The findings indicate a clear difference based on preferred service concepts and features between geographic locations. This suggests that a potentially interesting avenue for future research would be to look at the role of culture in CIS development. We are currently investigating how reasoning and values or goals in the laddering data could be used as ways to develop service concepts and how this would affect our understanding of requirements discovery activities.
Secondly, it was found that the Hong Kong participants identified with the mobile phone for personal identity, whereas the participants in Finland and USA did not. This was visible in the data set not only in relation to how participants provided reasoning for the service feature, but also in the way they perceived how they would gain utility from the service. The hedonic value drivers such as comfort, enjoyment, pleasure and selfactualization in life characterized the Hong Kong data set. By contrast, Finnish participants tended to emphasize communication efficiency, whereas Las Vegas participants had financial gains in mind. Although we realized that this finding could be potentially related to the sample of participants in Hong Kong (the majority of them were in their 20s and 30s), it is very interesting to find such a distinct difference in value drivers for mobile phone usage in different parts of the world. These findings were unexpected and led to the launch of another on-going research project that tries to investigate how culture influences the identity aspects of CIS use and development. The findings of the study are summarized in Table 7.

\section{Table 6 - Comparison of Service Concepts, based on (Tuunanen et al., 2006)}

\begin{tabular}{|l|c|c|c|c|l|}
\hline Service concept & Helsinki & Hong Kong & Las Vegas & Sig. & All \\
\hline City Reporter & $15.57 \%$ & $36.41 \%$ & $16.40 \%$ & .001 & $24.43 \%$ \\
\hline $\begin{array}{l}\text { Information Access for Special } \\
\text { Interest Groups }\end{array}$ & $30.33 \%$ & $11.52 \%$ & $9.52 \%$ & .001 & $15.15 \%$ \\
\hline Presence Messaging & $8.20 \%$ & $19.35 \%$ & $25.93 \%$ & .010 & $19.13 \%$ \\
\hline
\end{tabular}

\section{Table 7 - Findings from Mobile Presence Services Study}

\begin{tabular}{|c|c|c|c|}
\hline $\begin{array}{l}\text { Framework } \\
\text { Element(s) }\end{array}$ & Theoretical Approach & Findings & Future research topics \\
\hline $\begin{array}{l}\text { Construction of } \\
\text { Identities }\end{array}$ & $\begin{array}{l}\text { Social Actor Theory (Lamb, 2005, } \\
\text { Lamb, 2006, Lamb and Kling, 2003). } \\
\text { Thematic clustering of laddering } \\
\text { interview data (Tuunanen et al., } \\
\text { 2004, Tuunanen et al., 2006). }\end{array}$ & $\begin{array}{l}\text { Culture and/or geographic } \\
\text { location seems to drive } \\
\text { preference for mobile services }\end{array}$ & $\begin{array}{l}\text { Investigation of how } \\
\text { construction of identities can } \\
\text { be assisted by CIS }\end{array}$ \\
\hline $\begin{array}{l}\text { Customer } \\
\text { Goals and } \\
\text { Outcomes }\end{array}$ & $\begin{array}{l}\text { Hedonic Utility (Holbrook et al., 1984, } \\
\text { Kahneman et al., 2003), Consumer } \\
\text { trade-offs (Green and Srinivasan, } \\
\text { 1990, Ostrom and lacobucci, 1995) }\end{array}$ & $\begin{array}{l}\text { Clear differences in goals and } \\
\text { values of users between different } \\
\text { cultural regions. Different } \\
\text { preferences for service features. }\end{array}$ & $\begin{array}{l}\text { Development of alternative } \\
\text { ways to analyze } \\
\text { requirements data to reveal } \\
\text { cultural differences. }\end{array}$ \\
\hline
\end{tabular}




\section{Case Study 3: Interactive Television Services}

Description. The third and final study focused on how compelling end-user experiences can be incorporated into the development of interactive television services (Tuunanen et al., 2010). In this research project, the focus was on Internet Protocol TV (IPTV) based e-learning systems for tertiary education, where students can participate in a classroom from campus, home, or office with live interaction. More specifically, this research project looked at the development of an IPTV e-learning service at a premier research university in New Zealand. IPTV is defined as a system delivering digital television services to users using Internet protocol technology. Television content is transmitted over a high-speed broadband network. The project was conducted from 2007-2009.
Data collection. Twenty-one individual laddering interviews were conducted with student participants within the business school at the university. Potential lead-users in technologies relevant to IPTV were selected, such as those that were high users of online chat, online streaming media, and/or social networking websites. The data were analyzed using thematic clustering analysis (Tuunanen et al., 2004, Tuunanen et al., 2006). The demographic information of the interviewees is described in Table 8 below. The table shows a typical age distribution of undergraduate students in New Zealand. Most of the interviewees were majoring in IS, which explains the dominance of $2^{\text {nd }}$ and $3^{\text {rd }}$ year students. With this case study, males also dominated the gender distribution.

Findings. The findings of this study provide some evidence for the need to focus on the social use of information systems as suggested earlier (Lamb and Kling, 2003).

\begin{tabular}{|l|l|c|}
\hline \multicolumn{2}{|l}{ Table 8 - Demographics for the Interactive Television Services Study } \\
\hline Age & & \\
\hline & Under 20 & 8 \\
\hline & $20-24$ years & 11 \\
\hline & $25-29$ & 1 \\
\hline & $30-34$ & 1 \\
\hline Education & & \\
\hline & 3rd year undergraduate student & 6 \\
\hline & 2nd year undergraduate student & 13 \\
\hline & 1st year undergraduate student & 2 \\
\hline Gender & & \\
\hline & Male & 17 \\
\hline & Female & 4 \\
\hline
\end{tabular}

As the result of the requirements discovery exercise, seven service concepts for an Internet Protocol Television (IPTV) based elearning system emerged. These were related to content management, content delivery, content availability, interactive learning, collaborative learning, user interface features, and personalized learning space (see Table 9 for descriptions). These led to a requirements specification for an IPTV based e-learning system, which included 870 individual requirements. More specifically, collaborative learning and interactive learning related requirements showed that students 
expect social networking type features to enable learning. These include video conferencing, ranking of learning content and visual avatars for presenting one's identity etc. This finding indicates that as the social nature of information systems use is becoming more important, then we need to study how this affects not only the design and development of IS, but also the expected goals and outcomes of systems use. This raises an interesting question about how this might affect user acceptance (Venkatesh et al., 2003) of such systems and our current understanding of how this could be measured.

Next, we analyzed the data set to see how the "flow concept" impacts the perceived use of the proposed system (Agarwal and Karahanna, 2000, Csikszentmihaly, 1991, Hill et al., 2002). More specifically, we looked at how consumers of such services would like to be engaged with the developed CIS and the usefulness of the concept of flow. We found evidence of experiential and goal-directed consumption behaviors in all seven IPTV service concepts. Furthermore, two distinct categories of service concepts emerged. The concepts that generally describe characteristics for experiential uses include learning oriented feature sets such as "Collaborative Learning", "Interactive Learning", "Personalized Learning Space", and "User Interface Features", whereas, the concepts "Content availability", "Content Management", and "Content Delivery" generally depict uses for goal-directed consumption behaviors.

The findings indicate that all seven themes relate in some way to the concept of flow. Finally, the results indicate that the study participants valued the experience of flow in the online learning environment and that the experience of flow does play a role in the design of interactive technologies for consumers. The findings also suggest that as part of users' cognitive thinking processes, consumers value experiences that engage them in their learning (as opposed to being merely passive). The findings are summarized in Table 10.

\begin{tabular}{|l|l|}
\hline \multicolumn{1}{|c|}{ Table 9 - IPTV Service Concepts } \\
\hline Content Delivery & \multicolumn{1}{c|}{ Descriptions } \\
\hline Content Availability & $\begin{array}{l}\text { Wecture material, external links, user log history, pause \& skip } \\
\text { hard drive }\end{array}$ \\
\hline Content Management & Updated content, search, notifications, reminders \& alerts \\
\hline Collaborative Learning & $\begin{array}{l}\text { Forum, conferencing, sharing \& uploading content, content rating, } \\
\text { user recommended content \& popular content }\end{array}$ \\
\hline Interactive Learning & $\begin{array}{l}\text { Quiz, games for learning, virtual classroom, tagging, user } \\
\text { generated content, user comments \& notes section }\end{array}$ \\
\hline $\begin{array}{l}\text { Personalized } \\
\text { Space }\end{array}$ & $\begin{array}{l}\text { Personalized content, music \& configuring the system to more } \\
\text { personal }\end{array}$ \\
\hline User Interface Features & $\begin{array}{l}\text { Configuring the system, how it looks \& how information is } \\
\text { presented }\end{array}$ \\
\hline
\end{tabular}


Table 10 - Findings from Interactive Television Services Study

\begin{tabular}{|l|l|l|l|}
\hline $\begin{array}{c}\text { Framework } \\
\text { Element(s) }\end{array}$ & \multicolumn{1}{|c|}{ Theoretical Approach } & \multicolumn{1}{|c|}{ Findings } & \multicolumn{1}{|c|}{$\begin{array}{c}\text { Future Research } \\
\text { Topics }\end{array}$} \\
\hline $\begin{array}{l}\text { Social nature } \\
\text { of Use }\end{array}$ & $\begin{array}{l}\text { In-depth Laddering interviews } \\
\text { (Peffers et al., 2003). Social Actor } \\
\text { Theory (Lamb, 2005, Lamb, } \\
2006, \text { Lamb and Kling, 2003) }\end{array}$ & $\begin{array}{l}\text { Social networking tools were } \\
\text { expected features" of the } \\
\text { system in the final } \\
\text { requirements specification } \\
\text { document. }\end{array}$ & $\begin{array}{l}\text { The increased } \\
\text { emphasis on the } \\
\text { social nature of IS } \\
\text { use }\end{array}$ \\
\hline $\begin{array}{l}\text { Service } \\
\text { Process } \\
\text { Experience }\end{array}$ & $\begin{array}{l}\text { Exploration of using Flow in } \\
\text { developing interactive services } \\
\text { (Agarwal and Karahanna, 2000, } \\
\text { Csikszentmihaly, 1991, Hill et al., } \\
\text { 2002) }\end{array}$ & $\begin{array}{l}\text { The concept of flow seems to } \\
\text { be important for consumers in } \\
\text { order for them to experience } \\
\text { pleasure and enjoyment from } \\
\text { CIS use. }\end{array}$ & $\begin{array}{l}\text { Incorporation of the } \\
\text { flow concept into IS } \\
\text { development } \\
\text { methodologies. }\end{array}$ \\
\hline
\end{tabular}

\section{Discussion}

We have proposed a framework for the cocreation of value in consumer information systems. The framework implies a reconceptualization of information systems development for digital services with a focus on consumers instead of organizational users. The framework includes six elements that need to be considered in CIS development; these are further divided into system value propositions and customer value drivers. System value propositions consist of 1) social nature of use, 2) construction of identities, and 3 ) the context of use; customer value drivers include 1) customer participation in service production, 2) the service process experience, and 3) customer goals and outcomes associated with system use. Customer goal and outcome setting may differ between consumers and organizational users, particularly in terms of the balance between hedonic and utilitarian use of the systems.

In order to demonstrate the potential usefulness of our framework, we analyzed three case studies. Our findings reveal that the laddering interviewing technique [Peffers et al., 2003, Reynolds and Gutman, 1988] can contribute towards our understanding of how consumers construct their identities based on CIS use. Our findings indicate that the lead user approach can also be used for understanding the tacit needs and requirements of consumers. Further studies should be done, however, to understand the social nature of CIS use and how this might affect requirements discovery and user acceptance of CIS. When considering the impact of CIS use on service process experience, the concept of flow appears to be useful in helping us to understand how hedonic benefit is created by CIS. The challenge remains, however, how to integrate the concept of flow into the actual CIS development process. This brings us to the problem of discovering customer goals and desired customer outcomes.

Our findings concur with earlier research [Kujala, 2003, e.g., Tait and Vessey, 1988] that has shown user participation to be beneficial for IS project success. However, it is more difficult to say how and when this participation should occur, particularly in relation to value co-creation in CIS. Our findings indicate that the lead user approach can be used, at least on ad hoc basis, for understanding tacit needs and requirements of consumers. This approach has been challenged, however, with questions raised about how it can be used repeatedly in development work [Olson and Bakke, 2001]. The question remains: what to take account of when developing these systems for global markets? 


\section{Conclusions}

This paper is motivated by the shift towards service-oriented economies in the developed world and the emergence of a new research field, called service science (IfM and IBM, 2008). This shift has several implications for IS researchers.

Firstly, we need research about how to design and develop digitized services. Secondly, any new development method needs to take account of the fact that digitized services are increasingly targeted to consumers instead of organizational users. Finally, recent research indicates that consumption is motivated by the predicted utility of the good or service and that consumers use both rational (utilitarian) and emotional-based (hedonic) assessments of utility in their consumption decisions. This suggests the need for a reappraisal of information systems development methods for digitized services.

We have proposed a framework for the development of digitized services. Our framework includes six elements that need to be considered in CIS development; these are further divided into system value propositions and customer value drivers. System value propositions consist of 1) social nature of use, 2) construction of identities, and 3) the context of use; customer value drivers include 1) customer participation in service

\section{Reference}

Agarwal, R. and E. Karahanna (2000) "Time Flies When You're Having Fun: Cognitive Absorption and Beliefs about Information Technology Usage," MIS Quarterly, 24 (4), pp. 665-694.

Bergman, M., J. L. King, and K. Lyytinen (2002) "Large Scale Requirements Analysis Revisited: The Need for Understanding the Political Ecology of Requirements Engineering," Requirements Engineering, 7 (3), pp. 152-171. production, 2) the service process experience, and 3) customer goals and outcomes associated with system use.

We acknowledge that our proposed framework does not cover all the aspects of value co-creation in CIS. Our framework ignores issues such as the management of consumer information systems or their deployment into global markets; it also ignores more technical issues, such as the use of cloud computing and its integration into CIS. However, we believe that our proposed framework for the development of digitized services, focusing as it does on the co-creation of value for consumers, is one possible way forward.

Currently, we are continuing to investigate one of the emerging application areas of CIS in our research, namely Interactive Television Services. Our intention is to assist the TV industry to push the current envelope of provided services and create an Interactive Television Service platform for consumers. The objective is to provide further answers to the question of how we might be best utilize our framework to help ensure that CIS development methods contribute to the cocreation of value in consumer information systems.

Developed by Fabien Sanglard,
http://fabiensanglard.net/fluide/

Browne, G. J. and V. Ramesh (2002) "Improving information requirements determination: a cognitive perspective," Information \& Management, 39 (8), pp. 625-645.

Browne, G. J. and M. B. Rogich (2001) "An empirical investigation of user requirements elicitation: Comparing the effectiveness of prompting techniques," Journal of Management Information Systems, 17 (4), pp. 223249. 
Byrd, T. A., K. L. Cossick, and R. W. Zmud (1992) "A Synthesis of Research on Requirements Analysis and Knowledge Acquisition Techniques," MIS Quarterly, 16 (1), pp. 117-138.

Cavaye, A. L. M. (1995) "User participation in system development revisited," Information \& Management, 28 (5), pp. 311-323.

Creed, W. E. D., M. A. Scully, and J. R. Austin (2002) "Clothes Make the Person? The Tailoring of Legitimating Accounts and the Social Construction of Identity," Organization Science, 13 (5), pp. 475-496.

Csikszentmihaly, M. (1991) Flow: The Psychology of Optimal Experience. New York, USA: Harper Collins.

Davis, G. (1982) "Strategies for information requirements determination," IBM Systems Journal, 21 (1), pp. 4-31.

Dey, A. K. and G. D. Abowd. (2000) Towards a better understanding of context and context-awareness. 2000, pp. 304307.

Gengler, C. E. and T. J. Reynolds (1995) "Consumer Understanding and Advertising Strategy - Analysis and Strategic Translation of Laddering Data," Journal of Advertising Research, 35 (4), pp. 19-33.

Goodhue, D. L. (1995) "Understanding User Evaluations of Informations Systems," Management Science, 41 (12), pp. 1827-1844.

Green, P. E. and V. Srinivasan (1990) "Conjoint Analysis in Marketing: New Developments with Implications for Research and Practice," Journal of Marketing, 54 (4), pp. 3-19.

Griffin, A. and J. R. Hauser (1993) "The Voice of the Customer," Marketing Science 12 (1), pp. 1-27.

Grönroos, C. (2007) Service management and marketing - customer management in service competition. Chichester: Wiley.

Hartwick, J. and H. Barki (1994) "Explaining the role of user participation in information system use," Management Science, 40 (4), pp. 440-465.

Herzwurm, G., S. Schockert, and C. Weinberger. (1997) Customer Oriented Evaluation of QFD-Tools. Proceedings of the Third International Symposium on Quality Function Deployment, Linköping, Sweden, 1997, pp. 309-323 1.

Hickey, A. M. and A. Davis (2004) "A Unified Model of Requirements Elicitation," Journal of Management Information Systems, 20 (4), pp. 65-84.

Hill, A. V., D. A. Collier, C. M. Froehle, J. C. Goodale et al. (2002) "Research opportunities in service process design," Journal of Operations Management, 20 (2), pp. 189-202.

Holbrook, M. B., R. W. Chestnut, T. A. Oliva, and E. A. Greenleaf (1984) "Play as a Consumption Experience: The Roles of Emotions, Performance, and Personality in the Enjoyment of Games," Journal of Consumer Research (11) 2, pp. 728-739.

Holtzblatt, K. and H. Beyer (1993) "Making Customer-Centered Design Work for Teams," Communications of the Acm (36) 10, pp. 93-103

Holtzblatt, K. and S. Jones (1996) Contextual Design: Principles and Practice, in D. Wixon and J. Ramey (Eds.) Field Methods for Software and Systems Design, New York: John Wiley \& Sons.

IfM and IBM. (2008) Succeeding through service innovation: $A$ service perspective for education, research, business and government. University of Cambridge Institute for Manufacturing.

iWorthlt (2009) "Fluid iPhone App Review," http://www.iworthitappreviews.com/200 
9/05/11/fluid-iphone-app-review/ (31st August, 2009).

Jacobs, G. and B. Ip (2003) "Matching games to gamers with quality function deployment " Total Quality Management \& Business Excellence, 14 (9), pp. $959-967$.

Kahneman, D., E. Diener, and N. Schwarz (eds.) (2003) Well-Being : The Foundations of Hedonic Psychology, New York, NY: Russel Sage Foundations.

Karlsen, F. (2008) "Quests in Context: A Comparative Analysis of Discworld and World of Warcraft," Game Studies - The international journal of computer game research, 8 (1), online.

Keil, M. and E. Carmel (1995) "Customer Developer Links in SoftwareDevelopment," Communications of the ACM, 38 (5), pp. 33-44.

Kelly, G. (1955) The psychology of personal constructs. . New York: Norton.

Kujala, S. (2003) "User involvement: a review of the benefits and challenges," Behaviour \& Information Technology 22 (1), pp. 1-16.

Kujala, S., M. Kauppinen, and S. Rekola. (2001) Bridging the Gap between User Needs and User Requirements. Advances in Human-ComputerInteraction I (Proceedings of the Panhellenic Conference with International Participation in HumanComputer Interaction $\mathrm{PC}-\mathrm{HCl} 2001$, pp. 45-50.

Lamb, R. (2005) Modeling the Social Actor. the 12th European Conference on Information Technology Evaluation, Turku, Finland, 2005, pp. 7.

Lamb, R. (2006) Alternative Paths Toward a Social Actor Concept. the Twelfth Americas Conference on Information Systems, Acapulco, 2006, pp. 11.

Lamb, R. and R. Kling (2003) "Reconceptualizing Users as Social
Actors in Information Systems Research," MIS Quarterly, 27 (2), pp. $197-235$

Mathiassen, L., T. Saarinen, T. Tuunanen, and M. Rossi (2007) "A Contingency Model for Requirements Development," Journal of Association of Information Systems, 8 (11), pp. 569-597.

McKeen, J. D. and T. Guimaraes (1997) "Successful strategies for user participation in systems development," Journal of Management Information Systems, 14 (2), pp. 150.

Menor, L. J., M. V. Takikonda, and S. E. Sampson (2002) "New service development: areas for exploitation and exploration," Journal of Operations Management, 20 (2), pp. 135-157.

Myers, M. (1999) "Investigating information systems with ethnographic research," Communications of the AIS, 2 (4es), pp. 1-20.

Myers, M. D. and F. B. Tan (2003) "Beyond models of national culture in information systems research," Advanced topics in global information management, 10 (2), pp.1-19.

Olson, E. L. and G. Bakke (2001) "Implementing the lead user method in a high technology firm: A longitudinal study of intentions versus actions," Journal of Product Innovation Management, 18 (6), pp. 388-395.

Orlikowski, W. J., J. A. Yates, K. Okamura, and M. Fujimoto (1995) "Shaping electronic communication: the metastructuring of technology in the context of use," Organization Science (6) 4, pp. 423-444.

Ostrom, A. L., M. J. Bitner, S. W. Brown, K. A. Burkhard et al. (2010) "Moving Forward and Making a Difference: Research Priorities for the Science of Service " Journal of Service Research, 13 (1), pp. 4-36. 
Ostrom, A. L. and D. lacobucci (1995) "Consumer Trade-Offs and the Evaluation of Services," Journal of Marketing, 59 (1), pp. 17-28.

Pedersen, P. E. (2005) "Adoption of Mobile Internet Services: An Exploratory Study of Mobile Commerce Early Adopters," Journal of Organizational Computing and Electronic Commerce 15 (2), pp. 203-222.

Peffers, K., C. Gengler, and T. Tuunanen (2003) "Extending Critical Success Factors Methodology to Facilitate Broadly Participative Information Systems Planning," Journal of Management Information Systems, 20 (1), pp. 51-85.

Peffers, K. and T. Tuunanen (2005) "Planning for IS applications: a practical, information theoretical method and case study in mobile financial services," Information \& Management 42 (3), pp. 483-501.

Reynolds, T. J. and J. Gutman (1988) "Laddering Theory, Method, Analysis, and Interpretation," Journal of Advertising Research, 28 (1), pp. 1131.

Rockart, J. F. (1979) "Chief executives define their own data needs," Harvard Business Review, 52 (2), pp. 81-93.

Rogers, E. M. (1995) Diffusion of Innovations, 4th edition. New York: The Free Press.

Schilit, B., N. Adams, and R. Want. (1994) Context-Aware Computing Applications. First Workshop on Mobile Computing Systems and Applications, Santa Cruz, CA, 1994, pp. 85-90.

Shiv, B. and A. Fedorikhin (1999) "Heart and Mind in Conflict: the Interplay of Affect and Cognition in Consumer Decision Making," Journal of Consumer Research, 26 (3), pp. 278-292.

Simon, B., K. Boudreau, and M. Silverman (2009) "Two Players: Biography and 'Played Sociality' in EverQuest," Game
Studies - The international journal of computer game research, 9 (1), online.

Tait, P. and I. Vessey (1988) "The effect of user involvement on system success: a contingency approach," MIS Quarterly, (12) 1, pp. 91-108.

Thompson, C. (2009) Halo 3: How Microsoft Labs Invented a New Science of Play, in Wired Magazine.

Tuunanen T., H. Cassab, and H. Govindji (2010) Manifestation of flow in user requirements and its effects for requirements prioritization activities. Acta Unversitatis Ouluensis, Scientiae Rerum Naturalium. University of Oulu.

Tuunanen, T., K. Peffers, and C. Gengler. (2004) Wide Audience Requirements Engineering (WARE): a Practical Method and Case Study. Helsinki School of Economics W-378.

Tuunanen, T., K. Peffers, C. Gengler, W. Hui et al. (2006) "Developing Feature Sets for Geographically Diverse External End Users: A Call for Value-based Preference Modeling," JITTA : Journal of Information Technology Theory \& Application, 8 (2), pp. 41-55.

Tuunanen, T. and M. Rossi. (2004) Engineering a Method for Wide Audience Requirements Elicitation and Integrating It to Software Development. 37th Hawaii Int. Conference on System Sciences, Big Island, Hawaii, USA, 2004, pp. 10.

Vargo, S. L. and R. F. Lusch (2004) "Evolving to a New Dominant Logic for Marketing," Journal of Marketing, (68) January 2004, pp. 1-17.

Venkatesh, V., M. G. Morris, G. Davis, and F. Davis (2003) "User Acceptance of Information Technology: Toward a Unified View," MIS Quarterly, 27 (3), pp. 425-278.

von Hippel, E. (1986) "Lead Users: A Source of Novel Product Concepts," 
Management Science, 32 (7), pp. 791805.

von Hippel, E. (2001) "Innovation by user communities: Learning from opensource software," Sloan Management Review, 42 (4), pp. 82-86.

von Hippel, E. and R. Katz (2002) "Shifting innovation to users via toolkits," Management Science, 48 (7), pp. 821833.
Westbrook, R. A. and R. L. Oliver (1991) "The Dimensionality of Consumption Emotion Patterns and Consumer Satisfaction," Journal of Consumer Research, 18 (1), pp. 84-91.

Wölfl, A. (2005) "The service economy in OECD countries," Enhancing the Performance of the Services Sector pp. 27. 


\section{About the Authors}

Tuure Tuunanen is Senior Research Fellow in the Department of Information Processing Science at the University of Oulu. He holds a D.Sc. (Econ) in information systems and M.Sc. (Econ) in marketing from Helsinki School of Economics. His current research interests lie in the areas of IS development methods and processes, requirements engineering, risk management, and convergence of IS and marketing disciplines, specifically in design of interactive consumer services and products. Dr. Tuunanen is a CoEditor-in-Chief of Journal of Information Technology Theory and Application (JITTA).

Michael D. Myers is Professor of Information Systems and Head of the Department of Information Systems and Operations Management at the University of Auckland Business School, Auckland, New Zealand. His research articles have been published in many journals and books. He won the Best Paper award (with Heinz Klein) for the most outstanding paper published in MIS Quarterly in 1999. This paper has been cited over 1500 times and is third most cited paper to appear in MIS Quarterly. He also won the Best Paper Award (with Lynda Harvey) for the best paper published in Information Technology \& People in 1997. He currently serves as Senior Editor of Information Systems Research and as Editor of the ISWorld Section on Qualitative Research. He previously served as Senior Editor of MIS Quarterly from 2001-2005 and as Associate Editor of Information Systems Journal from 1995-2000. He also served as President of the Association for Information Systems (AIS) in 2006-2007 and as Chair of the International Federation of Information Processing (IFIP) Working Group 8.2 from 2006-2008. Michael is a Fellow of the Association for Information Systems.

Harold Cassab (PhD Washington) is a Senior Lecturer in Marketing at the University of Auckland, New Zealand. His current research interests include product and service design strategies and consumer response to product and service design. 